\title{
Economic evaluations in community aged care: a systematic review
}

\author{
Norma B. Bulamu ${ }^{1 *}$ (D) Billingsley Kaambwa ${ }^{1}$ and Julie Ratcliffe ${ }^{2}$
}

\begin{abstract}
Background: This paper reports the methods and findings from a systematic review of economic evaluations conducted in the community aged care sector between 2000 and 2016.

Methods: Online databases searched were PubMed, Medline, Scopus, and web of science, CINAHL and informit. Studies were included if they 1) were full economic evaluations that compared both the costs and outcomes of two or more interventions 2) in study population of people aged 65 years and over 3) dependent older people living in the community 4) alternatives being compared were care models or service delivery interventions in the community aged care sector (a group of programs that have been established as a support system to allow older people to remain living in their own homes for as long as possible, as an alternative to institutional or residential care) and 5) published in the English language between 2000 and November 2016.
\end{abstract}

Results: Eleven studies reporting upon economic evaluations of service delivery interventions in community aged care were identified; the majority of which were undertaken in Europe. Critical appraisal of the identified studies highlighted the methodological rigour in these evaluations.

Conclusion: This systematic review highlights the paucity of economic evaluation studies conducted to date in the community aged care sector. The findings highlight the importance of cost utility analysis methodology as it allows for a uniform outcome measure, that facilitates the comparison of different interventions. In addition, multi-attribute utility measures that represent those quality of life domains that are most important to older people should be used and attention must be paid to the inclusion of informal care costs and outcomes as this is a key resource in community aged care service delivery.

Keywords: Economic evaluation, Community aged care, Systematic review, Aged

\section{Background}

The World Health Organisation (WHO) has defined older people as persons who are 65 years or older [1] while the United Nations (UN) has classified persons over 60 years of age as older people [2]. By 2050, over 2 billion (22\%) of the world's population will be comprised of people aged over 60 years of age and of these, 402 million individuals will be over 80 years. Increased aging is associated with increases in dependency and frailty which creates additional demands upon health and aged care services [3]. Older

\footnotetext{
* Correspondence: norma.bulamu@flinders.edu.au

${ }^{1}$ Health Economics Unit, Flinders Health Care and Workforce Innovations,

School of Medicine, Flinders University, Adelaide, SA, Australia

Full list of author information is available at the end of the article
}

age in Australia is defined as in the majority of developed countries as the retirement age or eligibility age for pension funds of $65+$ years. Increased demand for aged care services coupled with scarce and constrained resources in this sector requires a review of existing policies and new approaches in the provision of aged care to ensure the efficient allocation of scarce resources i.e. in a manner that makes society better off rather than worse off $[4,5]$.

Aged care services in most developed countries are provided as government subsidies for older people to continue living at home, as community aged care services or in institutional care facilities or nursing homes as residential aged care services. Older people can continue living in the community with support for activities

(c) The Author(s). 2018 Open Access This article is distributed under the terms of the Creative Commons Attribution 4.0 International License (http://creativecommons.org/licenses/by/4.0/), which permits unrestricted use, distribution, and 
of daily living and or instrumental activities of daily living while those who are highly dependent and in need of intensive care to support their activities of daily living tend to live in institutions also referred to as residential aged care facilities or care homes or nursing homes [6-8]. Aged care services are provided under different jurisdiction internationally such as social care services in the UK [9], long-term care services in the USA [10] and most European countries [11]. Community aged care services are also referred to as home care services, home-based care, care at home or home and community-based services [12]. Policy reforms in community aged care service provision internationally led to the introduction of consumer directed models of care which aim to improve older people's involvement in decision making with regard to the care that they receive [12-14]. However little evidence is currently available to assess the costs and outcomes associated with these policy reforms or to determine the cost effectiveness of models of care in the aged care sector $[15,16]$.

In contrast to the wide proliferation of economic evaluations reported upon in the health care sector, a paucity of economic evaluations have been conducted in community aged care [17]. Economic evaluation is defined as the comparative assessment of the cost and benefits of alternative interventions, also referred to as the comparators [18]. There are five main types of economic evaluation: cost minimisation analysis, cost effectiveness analysis, cost utility analysis, cost benefit analysis and cost consequence analysis [18]. The key feature that distinguishes the different types of economic evaluation is the unit for measuring the benefits of interventions in community aged care. Cost effectiveness analysis focuses upon a single measure of outcome, which is typically measured in natural units and is specific to the research question being addressed. Cost utility analysis is more generally focused on quantifying the quality of life benefits that older people may obtain from new innovations in aged care with the main measure of outcome being quality adjusted life years (QALYs) [18, 19].

The viewpoint or perspective of an economic evaluation is important as it determines the range of inputs/costs and outputs/outcomes to be considered in the economic evaluation. The societal perspective is the broadest perspective and is often advocated for use when evaluating publicly funded programs, where all costs and benefits to society as a whole irrespective of who incurs or receives them are considered $[18,20]$. Costs are categorised according to where they are incurred e.g. community aged care, residential aged care, health care sector, client/family costs (the private costs incurred by the client and their family in receiving care, productivity losses as a result of the provision of informal care) [18].

The main objectives of this systematic review were to i) capture the available evidence relating to the application of economic evaluation in the community aged care sector and ii) provide a critical appraisal of previous full economic evaluation studies that compared both the costs and outcomes of two or more interventions for dependent older people in community aged care and published in the English language (where dependency was defined as needing some assistance to perform activities of daily living through the receipt of informal care and/or community aged care services) iii) examining to what extent informal care was included and the methods used to value informal care e.g. productivity losses. The review focussed only on full economic evaluations because these are preferred to partial evaluations by decision making bodies internationally including the Medical Services Advisory Committee (MSAC) in Australia and the National Institute for Health and Care Excellence (NICE) in the UK $[21,22]$.

\section{Methods}

\section{Search strategy and selection criteria}

Database: PubMed, Medline, Scopus, CINAHL, informit, and Web of Science

Search terms:Three key concepts were considered and incorporated

i. the population was defined by subject headings such as aged; aged, frail and keywords such as elder or old age or older person or people or adult

ii. economic evaluation methodology was defined by headings including economics; quality-adjusted life years; costs and cost analysis and keywords economic analysis or evaluation or model, cost effectiveness or cost utility or cost benefit, quality adjusted life years or QALY

iii. community aged care sector was defined by subject headings such as Homes for the Aged; Independent Living and keywords such as community care or home care or community aged care or home living or community living

The search strategy used in Medline is presented in Table 1 below.

The study selection process followed the Preferred Reporting Items for Systematic Reviews and Meta-Analyses (PRISMA) guidelines for systematic reviews [23]. 
Table 1 Medline search strategy

\begin{tabular}{|c|c|}
\hline$\# \boldsymbol{\Delta}$ & Searches \\
\hline 1 & (community care or home care or community aged care).tw. \\
\hline 2 & $\begin{array}{l}\text { ((geriatric or elder or 'older people') adj2 (home* or apartment* } \\
\text { or residence*)).tw. }\end{array}$ \\
\hline 3 & $\begin{array}{l}\text { (((home or community) adj5 (dwelling or based or setting*)) or } \\
\text { (living adj5 (home or community or independent*))).tw. }\end{array}$ \\
\hline 4 & $\begin{array}{l}\text { ((community or home* or respite or social or aged) adj5 } \\
\left(\text { care }^{*} \text { or welfare* or support*)).tw. }\right.\end{array}$ \\
\hline 5 & $\begin{array}{l}\text { Homes for the Aged/ or Health Services for the Aged/ or Social } \\
\text { Welfare/ or Community Health Services/ or Independent Living/ }\end{array}$ \\
\hline 6 & or/1-5 \\
\hline 7 & economics/ or Quality-adjusted life years/ \\
\hline 8 & $\begin{array}{l}\text { exp "costs and cost analysis"/ or cost-benefit analysis/ or "cost of } \\
\text { illness"/ or exp. health care costs/ }\end{array}$ \\
\hline 9 & "Value of Life"/ec [Economics] \\
\hline 10 & $\begin{array}{l}\text { ((economic* adj1 (analys* or evaluat* or model*)) or (cost adj2 } \\
(\text { (effective* or utilit* or benefit or analysis or minimisation)) or } \\
\text { ("quality adjusted life year*" or qaly)).tw. }\end{array}$ \\
\hline 11 & or/7-10 \\
\hline 12 & Aged/ \\
\hline 13 & "aged, 80 and over"/ or frail elderly/ \\
\hline 14 & $\begin{array}{l}\text { (elder* or geriatric* or old age* or ((old* or aged) adj (person or } \\
\text { people* or adult*))).tw. }\end{array}$ \\
\hline 15 & (aged adj ("65" or "70" or "75" or " 80 " or " 85 ")).tw. \\
\hline 16 & or/12-15 \\
\hline 17 & 6 and 11 and 16 \\
\hline 18 & limit 17 to (english language and yr = "2000 - Current") \\
\hline
\end{tabular}

\section{Eligibility criteria}

1) studies comparing both costs and outcomes of two or more interventions undertaken as stand-alone studies or alongside a clinical trial or other types of study design, 2) study population exclusive to people aged 65 years and over, 3) dependent older people living in the community, 4) the alternatives being compared (also referred to as comparators) were care models or service delivery interventions in the aged care sector, 5) published in the English language in peer reviewed journals between 2000 and November 2016.

Studies were excluded if: 1) both costs and outcomes were not considered and compared e.g. a cost analysis with no consideration of outcomes, effectiveness studies with no cost measurement, studies with no comparators, burden of disease or cost of illness studies 2) study population was not exclusive to people aged 65 years and over 3) study population was not based in the community 4) theory papers, letters, editorials, reviews, theses or dissertations and studies where full texts could not be obtained.

Two reviewers assessed the articles for eligibility with the second reviewer independently assessing $20 \%$ of the articles. Overall agreement between reviewers for this sub-sample was calculated using Cohen's kappa statistic $[24]$. Both reviewers then undertook the quality assessment of included studies and one reviewer undertook the data extraction and data synthesis.

\section{Data extraction and synthesis}

The data in included studies was synthesised narratively to identify the key methodological principles applied. Full text articles of included studies were read to obtain the following categories of information: study design and type of evaluation, key comparators, perspective/viewpoint of the study, the cost categories considered, type of costing used and the source of costing data, definition of outcomes and how they were measured, and the key results and conclusions of the study.

\section{Quality assessment}

Economic evaluations that met the eligibility criteria were critically appraised using the critical appraisal checklist produced and disseminated by the University of Glasgow [25] that is based upon the guidelines developed by Drummond and colleagues [18].

Further assessment was undertaken to investigate the suitability of instruments applied in measuring quality of life and QALYs in the CUA studies and to examine the inclusion of and methods used to value informal care as a cost or outcome.

\section{Results}

\section{Study selection process}

Study selection was divided into four main stages (see Fig. 1):

i. Identification: 10,588 papers were identified from the database search and an additional 21 from backward and forward searching the reference lists of the final studies accepted for the review, 3119 duplicate articles were removed.

ii. Screening: 7490 titles and abstracts were screened for eligibility; 7354 papers did not meet the eligibility criteria.

iii. Eligibility: 136 studies full texts articles were read and further assessed; 85 studies did not compare care models or service delivery interventions in community aged care, 24 were cost analysis studies while the population in 10 studies was not exclusive to older people and the full text could not be obtained in six studies.

iv. Included: 11 economic evaluation studies were included in the qualitative synthesis and narrative review. Five studies were CEAs, five CUAs and one CCA. The level of agreement relating to study exclusion and inclusion between the two reviewers 


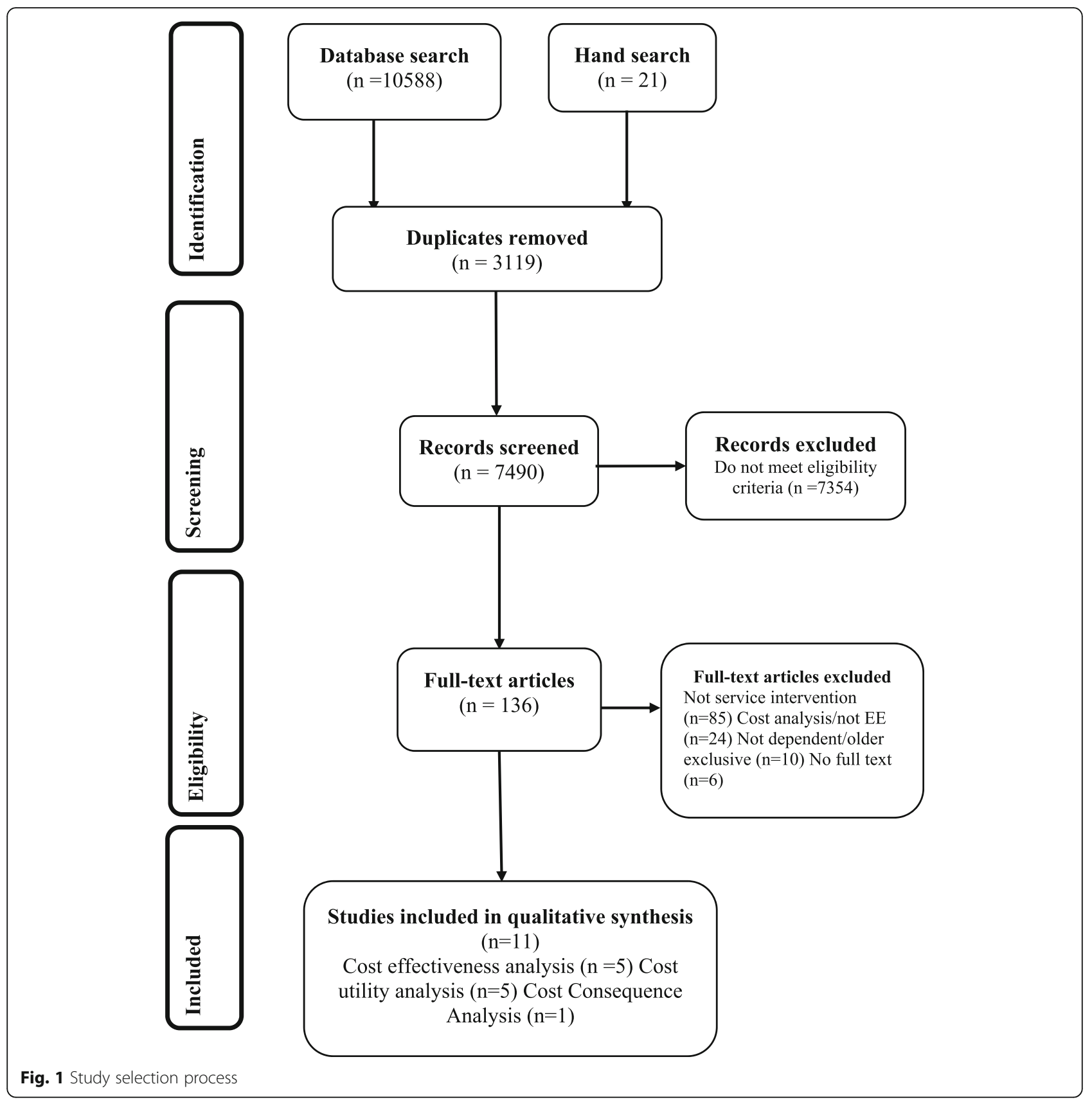

was very high/almost perfect with a kappa statistic of $0.82[26]$

\section{Key findings}

The geographical distribution of the studies varied widely with nearly three quarters (8 studies) undertaken in Europe, refer to Fig. 2.

The majority (8 studies) of the economic evaluations were undertaken alongside randomised controlled trials (RCT). One economic evaluation was undertaken based on data from a retrospective cohort, and two were quasi-experimental studies. The sample sizes reported upon in the identified studies varied greatly from a minimum of 153 to a maximum of over 10,000 participants (see Table 2).

The most prevalent types of evaluation were cost effectiveness analysis ( 5 studies) and cost utility analysis ( 5 studies) with one study reporting a cost consequence analysis. No studies were identified that used a costbenefit approach. The interventions in 10 studies pertained to structures and processes of care/service delivery. Four studies assessed the value of preventative home visits compared to usual care where older people received care from their general practitioner (GP) or 


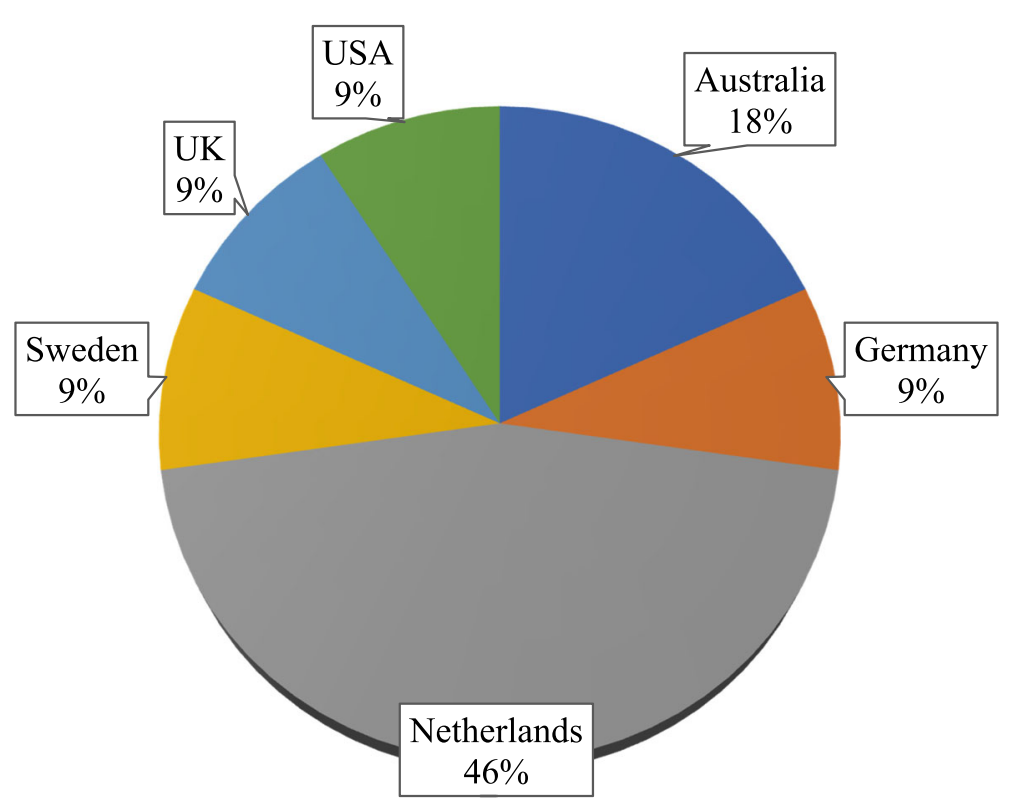

Fig. 2 Geographical distribution of identified studies

social services as and when it was needed [27-30]. Preventative home visits are designed to monitor the level of frailty and needs of older people, to preserve functional ability and subsequently delay admission to nursing homes or residential aged care facilities. One study assessed the cost effectiveness of re-ablement programs following hospital stay [31]. Four studies compared integrated multidisciplinary care interventions for frail older people to usual care where older people seek care from their GP as and when its needed. Integrated care programs were interventions that provided services to frail older people through coordinated multidisciplinary health teams [32, 33] and social care teams [34, 35]. Two studies compared interventions relating to the organisation of care; comparing different models for assessing older people's eligibility for aged care services [36] and the value of case management in improving older people's functional status and health care use [37]. Case management was an outreach service aimed at improving older people's access to and continuity of health care services through needs assessment, care planning, care coordination as well as monitoring and evaluation of the older person's needs.

The perspectives taken for the economic evaluations varied with six studies indicating that they had been undertaken from a societal perspective $[27,28,32,34$, $35,37]$, one study was undertaken from a health system perspective [30] and one study was undertaken from a service provider's perspective [29]. Two studies considered the public sector (both health and social care) perspective [33, 36] whilst no particular perspective was indicated for the remaining study [31]. The time horizon for the economic evaluation was predominantly one year and under (6 studies).

A summary of the included studies is provided in Table 2.

\section{Application of economic evaluation methodology Studies applying CUA methodology}

As indicated previously, five studies applied a CUA methodology. One study evaluated the cost effectiveness of preventive home visits compared to usual care for community dwelling older people in Germany with time horizon of 18 months [28], two studies assessed the value of different processes of care; Sandberg et al. evaluated the cost utility of case management programs in Sweden over 12 months [37] while Flood and colleagues (2005) compared the cost effectiveness of occupational therapist (OT) led and social worker (SW) led assessment of the needs of older people in the UK over 8 months [36]. All three evaluations were each undertaken alongside RCTs. The final two studies applying CUA methodology analysed the cost effectiveness of the Walcheren integrated care model (WICM) alongside a quasi-experimental study among frail community dwelling older people in the Netherlands at two different time points; a follow up period of 3 months [35] and 12 months [34].

All studies applied a societal perspective with the consideration of client and family costs including informal care costs except in one study that applied a public sector perspective [36]. A micro-costing approach was used 


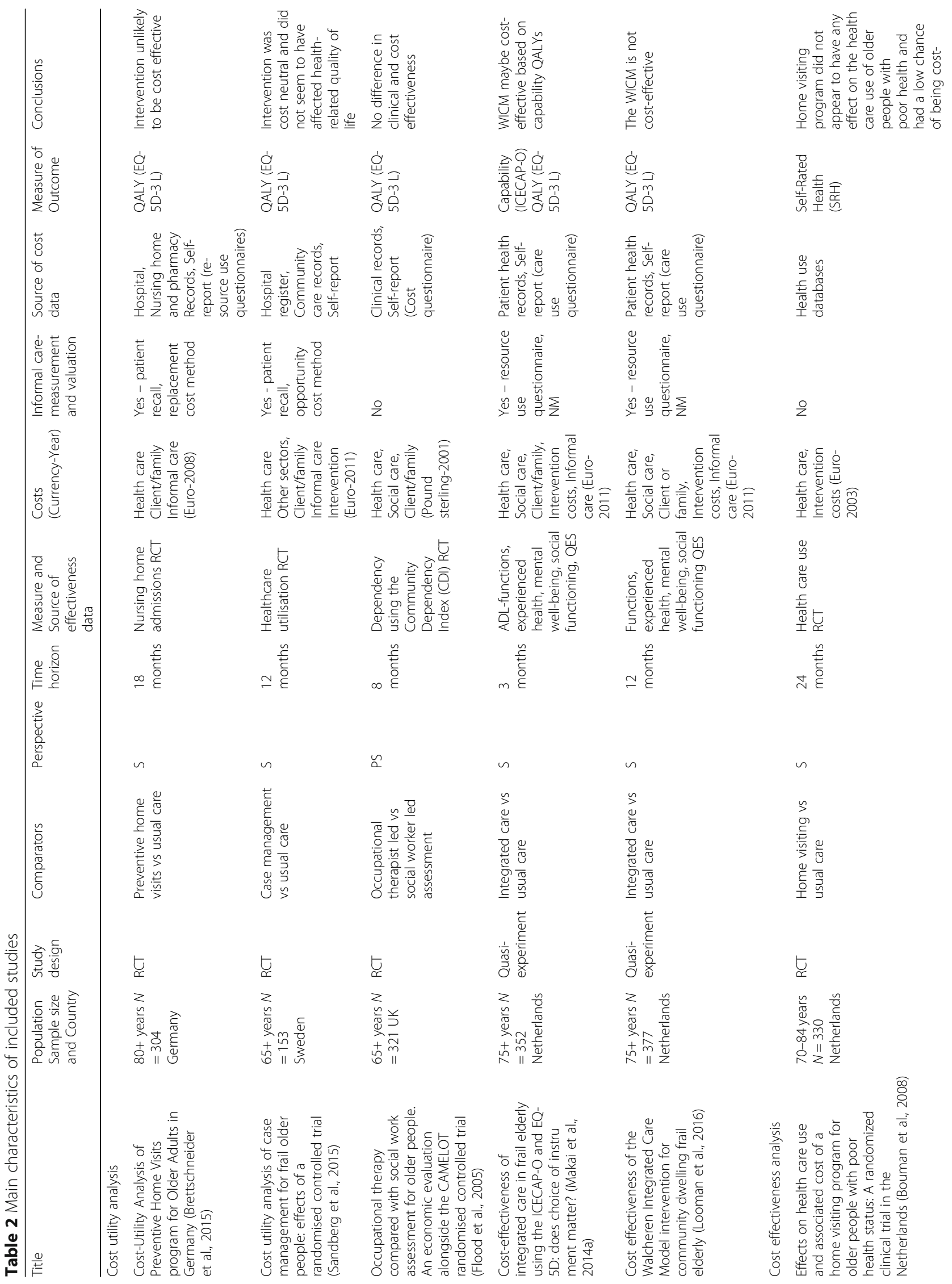




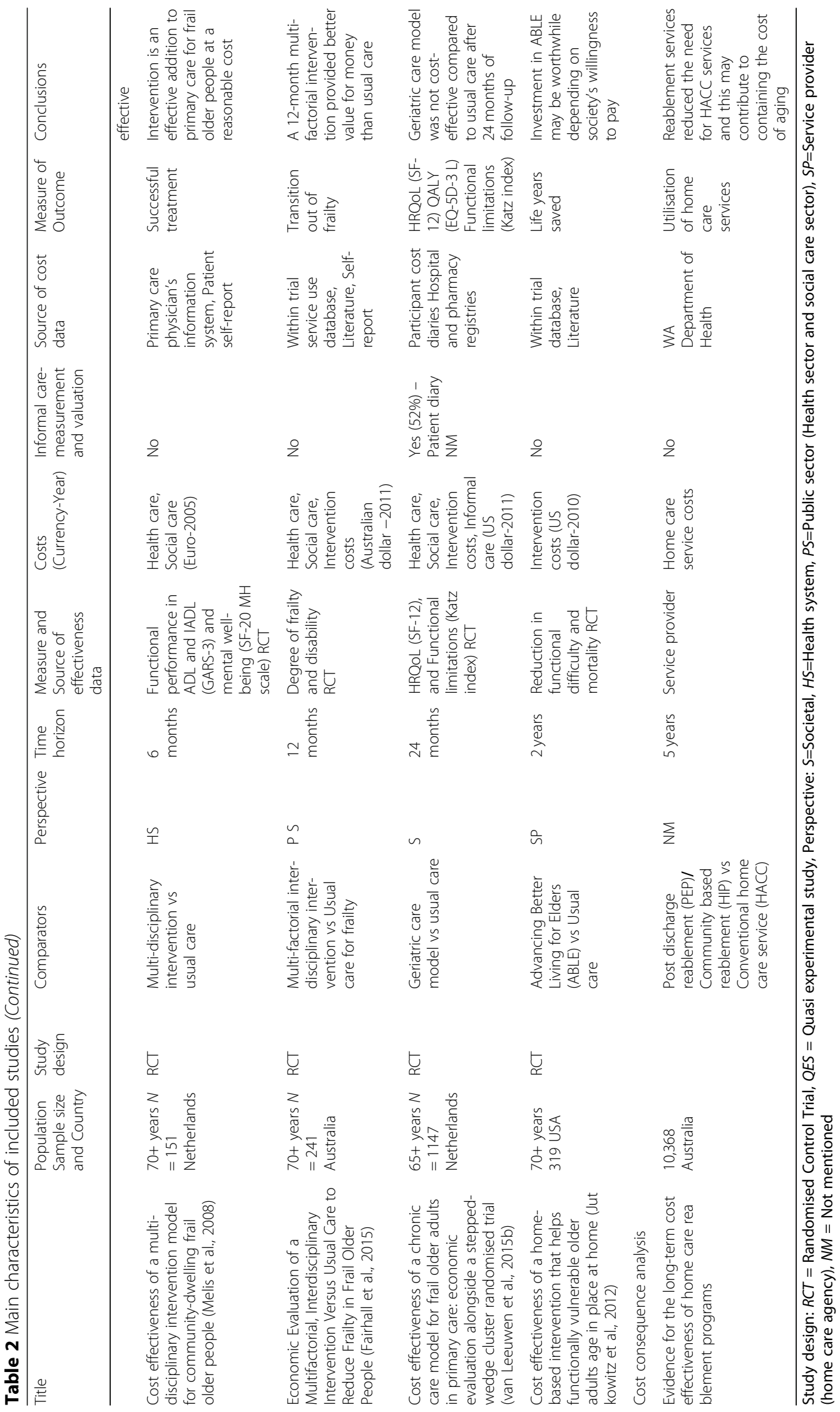


in all studies where client level data was obtained from records (hospital, nursing homes, social services and pharmacy) and self-report using resource use questionnaires.

The primary measure of outcome in all studies, the QALY, was measured using the EuroQol 5 Dimensions (EQ-5D-3 L) instrument, a multi-attribute utility measure of health status. One study [35] assessed quality of life using both the EQ-5D-3 L and the ICEpop CAPability measure for Older people (ICECAP-O), an older-person-specific measure of capability. Preventative visits did not improve quality of life and subsequently the intervention was not cost effective [28], and case management was found to be cost neutral compared to usual care [37] while OT led assessment was not cost effective compared to SW led assessment [36]. The last two studies highlighted the effect of the outcome measure on the results of an economic evaluation. There was no significant differences between WICM and usual care using the EQ-5D-3 L, a measure of health related quality of life (HRQoL) at 3 months [35] and even with a longer time horizon of 12 months [34]. However, there was a higher probability of cost effectiveness based on capability outcomes using the older-person-specific ICECAP-O [35].

\section{Studies applying CEA methodology}

Three studies applied CEA methodology. Two studies assessed the effectiveness of preventative home visiting programs to reduce frailty compared to usual care alongside RCTs in the Netherlands with time horizon of 24 months [27] and 6 months [30]. A societal perspective was adapted in the first study although only health care and social care costs were included with the exclusion of client/family costs as well as costs attributable to informal caring [27]. The second study assessed the Dutch Geriatric Intervention Program (DGIP), a preventative home visiting program, over 6 months under a health system perspective with the inclusion of health care and social care costs [30]. Both studies applied a micro-costing approach, using health records and client self-report for social care utilisation. Self-rated health (on ten-point Likert type scale ranging from poor to excellent) was the measure of outcome in the first study [27] while successful treatment was the measure of outcome in the second study; successful treatment was defined by improvement of functional performance in instrumental activities of daily living (assessed by the GARS-3) and mental wellbeing (assessed using the SF-20) [30]. The preventative program assessed by Bouman et al. was not found to be cost-effective compared to usual care while DGIP was cost-effective. Although these two studies evaluated closely similar interventions in the same setting (population and country), they cannot be directly compared because different measures of outcome were applied.

Another preventative intervention, Advancing Better Living for Elders (ABLE) was assessed alongside a RCT in the United States of America (USA) over a two-year study period [29]. The service provider's perspective was taken in this study with only direct /intervention costs included using a micro-costing approach and life years saved (LYS) as a measure of outcome. Cost effectiveness was analysed under two scenarios: using within trial data and extrapolation to the real world setting where costs were elevated by $10 \%$; ABLE was cost effective within the trial and in the real-world setting.

\section{Studies applying CEA and CUA methodology}

Two studies applied both CEA and CUA methodology in assessing the cost effectiveness of integrated care or multi-disciplinary approaches to the management of older people at home alongside RCTs. Fairhall et al. evaluated a multifactorial interdisciplinary health intervention for older people in Australia over 12 months [33] while van Leeuwen and colleagues assessed the cost effectiveness of the Geriatric Care Model (GCM) providing both health and social care services in the Netherlands over a 24-month period [32]. The public sector perspective was applied in Australia with the inclusion of health and social care costs. Both micro-costing and macro-costing approaches were used to obtain cost data with cost components including health and social care costs as well as direct intervention costs. The measure of effectiveness was transition out of frailty while quality of life was assessed using the EQ-5D-3 L. The intervention was found to be cost effective as more people transitioned out of frailty compared to usual care, however, there was no improvement in QALYs between the two groups and the ICER was not calculated for the CUA.

Van Leeuwen et al. applied a societal perspective including health and social care costs as well as the cost of informal care using a micro-costing approach (data obtained from hospital and pharmacy records as well as client cost diaries). Four measures of outcome were considered in this study; primary outcome was HRQoL measured by the short-form 12 health questionnaire (SF-12) and secondary outcomes were QALYs based on the EQ-5D-3 L and functional limitations in activities of daily living measured using the Katz basic activity of daily living scale. There were no differences in all outcomes between the two alternatives and the GCM was not found to be cost effective compared to usual care.

Similar to Makai et al. (2014) under CUA, there was no significant change in HRQoL between the intervention and control group using the EQ-5D-3 L $[32,33]$ and the SF-12 [32] in the two studies above, which may 
suggest that HRQoL measures may not be sensitive when applied in assessing interventions for older people.

\section{Studies applying CCA methodology}

To compare the value for money of a home care re-ablement program against conventional home and community care (HACC) in Australia, a CCA was conducted based on retrospective data over 5 years [31]. Re-ablement services were comprised of post-discharge re-ablement (PEP) for older people discharged from hospital back to the community and community based re-ablement (HIP) offered to community dwelling older people seeking to improve their levels of function. The service provider's perspective was adapted for this study and only home care service costs were included, with the utilisation of HACC services as the measure of outcome. Re-ablement services reduced the need for HACC services and therefore contain the cost of aged care services.

\section{Critical appraisal of evaluations}

Nine studies were satisfactorily conducted when assessed according to the critical appraisal criteria (all twelve questions). One study each were satisfactory in 11 questions [27] and 10 questions [31].

As the majority of economic evaluations were undertaken alongside clinical trials, the effectiveness of the intervention/s under consideration tended to be clearly established [27, 29, 30, 32, 33, 36-38]. The economic evaluations based on other study designs demonstrated effectiveness through a synthesis of evidence collated from review of literature [31, 34, 35]. Costs and outcomes were comprehensively identified and measured in all studies with the exception of one study that was reported as undertaken from a societal perspective but did not report costs associated with the provision of informal care [27]. All studies with time horizons beyond one year discounted both costs and outcomes at the appropriate rates based on the country where the study was undertaken. Notably, the CUA studies were all of high methodological quality ranking positive on all critical appraisal questions. A summary of the results of the critical appraisal assessment based on the University of Glasgow critical appraisal checklist is presented in Table 3.

\section{Measuring QALYs and HRQOL}

In measuring QALYs, all of the studies [28, 34-37] applied the EQ-5D measure. Two studies using HRQoL as a measure of effectiveness applied the SF-12 [32] and SF-20 [30]. The EQ-5D is a multi-attribute utility measure of quality of life assessing dimensions including mobility, self-care, usual activities, pain/discomfort and anxiety/depression [39]. The SF-12 and SF-20 are shorter versions of the generic HRQoL measure SF-36 which assesses eight dimensions of quality of life using 36 questions [40]. The SF-12 contains 12 questions assessing the original eight dimensions including physical functioning, role-physical, bodily pain, general health, vitality, social functioning, role-emotional and mental health [41] while the SF-20 has 20 questions assessing physical functioning, role functioning, bodily pain, current health perspective, social functioning and mental health [42].

\section{Informal care}

At least $30 \%$ of participants in all included studies reported themselves as having an informal carer but only 5 studies incorporated the cost of informal care. This could be attributed to the narrow perspectives applied in some studies, for example although $75 \%$ of participants in one study [30] reported themselves as having an informal carer, the cost of informal care was not considered because the study was conducted under a health sector perspective. Five of the six studies conducted under a societal perspective included the cost of informal care $[28,32,34,37,43]$ but none considered the effect of the caring role on carer's quality of life or informal care on the outcomes side of the equation. Informal care was measured through patient recall $[28,37]$ or resource use questionnaires completed by the client or the informal carer $[32,34,43]$ and none reported whether informal care was provided at the same time as other activities such as leisure activities or joint production. It was valued using the opportunity cost method using the average wage rate [37] or the replacement cost method using the wage of a paid carer [28] but the method of valuation not mentioned in the remaining three studies. Informal care was a key cost driver in two studies; making the intervention costlier through increased use [32] and less costly through reduced use [37]. Sandberg et al., 2005 found no significant differences in costs or quality of life between the intervention and usual care but the need for informal care declined in the intervention group [37].

\section{Discussion}

This systematic review has highlighted the paucity of economic evaluation studies conducted in the community aged care sector. The most prevalent types of economic evaluation methodologies applied were cost effectiveness analysis and cost utility analysis.

Whilst a study focusing upon CCA was included in this review, CCA does not aggregate costs and outcomes to give an indication of the incremental cost effectiveness associated with the competing alternatives [18, 44]. It has been suggested however, that this type of analysis may allow the decision maker more flexibility to select 
Table 3 Results of the critical appraisal

\begin{tabular}{|c|c|c|c|c|c|c|c|c|c|c|c|c|}
\hline \multirow[t]{2}{*}{ Study reference } & \multicolumn{3}{|c|}{$\begin{array}{l}\text { Is the EE } \\
\text { likely to be } \\
\text { usable }\end{array}$} & \multicolumn{6}{|c|}{$\begin{array}{l}\text { How were costs and } \\
\text { outcomes assessed and } \\
\text { compared }\end{array}$} & \multicolumn{3}{|c|}{$\begin{array}{l}\text { Will the results } \\
\text { help in } \\
\text { purchasing for } \\
\text { local people }\end{array}$} \\
\hline & Q1 & Q2 & Q3 & $\mathrm{Q} 4$ & Q5 & Q6 & Q7 & Q8 & Q9 & Q10 & Q11 & Q12 \\
\hline $\begin{array}{l}\text { Cost-Utility Analysis Of Preventive Home Visits program for Older } \\
\text { Adults in Germany [38] }\end{array}$ & Yes & Yes & Yes & Yes & Yes & Yes & No & Yes & Yes & Yes & Yes & Y \\
\hline $\begin{array}{l}\text { Cost utility analysis of case management for frail older people: } \\
\text { effects of a randomised controlled trial [37] }\end{array}$ & Yes & Yes & Yes & Yes & Yes & Yes & $\begin{array}{l}\mathrm{N} / \\
\mathrm{A}^{*}\end{array}$ & No & Yes & Yes & Yes & Ye \\
\hline $\begin{array}{l}\text { Occupational therapy compared with social work assessment for } \\
\text { older people. An economic evaluation alongside the CAMELOT } \\
\text { randomised controlled trial [36] }\end{array}$ & Yes & Yes & Yes & Yes & Yes & Yes & $\begin{array}{l}N / \\
A^{*}\end{array}$ & Yes & Yes & Yes & Yes & Y \\
\hline $\begin{array}{l}\text { Cost-effectiveness of integrated care in frail elderly using the ICECAP-O } \\
\text { and EQ-5D: does choice of instrument matter? [35] }\end{array}$ & Yes & Yes & Yes & Yes & Yes & Yes & $\begin{array}{l}\mathrm{N} / \\
\mathrm{A}^{*}\end{array}$ & Yes & Yes & Yes & Yes & Ye \\
\hline $\begin{array}{l}\text { Cost effectiveness of the Walcheren Integrated Care Model intervention } \\
\text { for community dwelling frail elderly [34] }\end{array}$ & Yes & Yes & Yes & Yes & Yes & Yes & $\begin{array}{l}\mathrm{N} / \\
\mathrm{A}^{*}\end{array}$ & Yes & Yes & Yes & Yes & Ye \\
\hline $\begin{array}{l}\text { Effects on health care use and associated cost of a home visiting program } \\
\text { for older people with poor health status: A randomized clinical trial in the } \\
\text { Netherlands [27] }\end{array}$ & Yes & Yes & Yes & No & Yes & Yes & Yes & Yes & Yes & Yes & Yes & \\
\hline $\begin{array}{l}\text { Cost effectiveness of a multi-disciplinary intervention model for community- } \\
\text { dwelling frail older people [30] }\end{array}$ & Yes & Yes & Yes & Yes & Yes & Yes & $\begin{array}{l}\mathrm{N} / \\
\mathrm{A}^{*}\end{array}$ & Yes & Yes & Yes & Yes & \\
\hline $\begin{array}{l}\text { Economic Evaluation of a Multifactorial, Interdisciplinary Intervention } \\
\text { Versus Usual Care to Reduce Frailty in Frail Older People [33] }\end{array}$ & Yes & Yes & Yes & Yes & Yes & Yes & $\begin{array}{l}\mathrm{N} / \\
\mathrm{A}^{*}\end{array}$ & Yes & Yes & Yes & Yes & \\
\hline $\begin{array}{l}\text { Cost effectiveness of a chronic care model for frail older adults in primary care: } \\
\text { economic evaluation alongside a stepped-wedge cluster randomised trial [32] }\end{array}$ & Yes & Yes & Yes & Yes & Yes & Yes & Yes & Yes & Yes & Yes & Yes & Ye \\
\hline $\begin{array}{l}\text { Cost effectiveness of a home-based intervention that helps functionally } \\
\text { vulnerable older adults age in place at home [29] }\end{array}$ & Yes & Yes & Yes & Yes & Yes & Yes & Yes & Yes & Yes & Yes & Yes & Ye \\
\hline $\begin{array}{l}\text { Evidence for the long-term cost effectiveness of home care re-ablement } \\
\text { programs [31] }\end{array}$ & Yes & Yes & Yes & Yes & C & Yes & $\mathrm{N}^{*}$ & $\mathrm{~N}^{*}$ & C & Yes & Yes & \\
\hline
\end{tabular}

Q1: Well-defined question; Q2: Comprehensive description of alternative; Q3: Evidence of effectiveness; Q4: Important/ relevant outcomes and costs identified; Q5: Outcomes and costs measured accurately in appropriate units; Q6: Outcomes and costs valued credibly; Q7: Discounting; Q8: Incremental analysis of the outcomes and costs; Q9: Sensitivity analysis; Q10: Discussion of the results include issues that are of concern to purchasers; Q11: Conclusion justified by the evidence presented; Q12: Results applicable to local population; *N/A is considered as an answered question

those components of costs and outcomes that may be relevant to their decision and compute a cost effectiveness ratio if desired [44].

As observed in some of the studies, measurement of outcomes in natural units is a limitation of CEA as there is no standard measure of outcome and this affects the comparability of results between studies [30, 33]. In contrast, CUA facilitates direct comparisons between competing interventions most often through the calculation of QALYs, a generic measure of outcome. Cost utility analysis is recommended as the preferred approach for the economic evaluation of interventions in aged care and has also been highlighted as a useful framework for the conduct of economic evaluations by key funding bodies internationally [45-48]. A key issue for the conduct of CUA in the community aged care sector is the identification of appropriate instruments that capture the breadth of quality of life as defined by older people [33, 35, 36, 49]. Whilst widely validated measures such as the EQ-5D were applied in the studies identified in this review, HRQoL measures primarily focus on health and physical functioning and do not specifically address dimensions of quality of life that are most important to older people and may not be sensitive to quality of life improvements in this population [19, 32, 35, 50]. Several commentators have argued that to comprehensively reflect quality of life benefits of interventions to older people, one requires an instrument that not only measures health and physical functioning but includes dimensions that are important to older people in receipt of aged care particularly psychosocial functioning, the ability to be independent, control over daily lives and involvement in decision making, and also defines health as a resource to help them achieve their goals and facilitate social and physical participation [50-53]. Two reviews of instruments suitable for use in economic evaluations involving older people have highlighted the potential benefits of the use of preference based instruments such as the ICECAP-O and the Adult Social Care Outcomes Toolkit (ASCOT) which both have a focus on wider quality of life attributes beyond health status [43, 54]. Depending on the intervention under review, such instruments may be applied in combination with HRQoL instruments [55-57]. 
Some commentators have also argued that the QALY metric may not be a suitable measure for older people as its calculation is based on a combination of quality of life and length of life, which by default discriminates against older people with a shorter life expectancy $[52,58,59]$. Yet the derivation of value sets for most instruments with the QALY scale has been predominantly based on populations with younger age groups (18-64 years) and less representation of older people (over 65 years) $[5,60]$.

The Second Panel on Cost-Effectiveness in Health and Medicine recommends that results of economic evaluations should be reported from a societal perspective as a reference case with the inclusion of informal care costs [61]. A review of the inclusion of informal care in applied economic evaluation found that only a small proportion of studies formally included informal care [62]. Our findings were consistent with this review. Although most study participants (at least 30\% in all studies) reported themselves as having an informal carer, only five studies considered the cost of informal care and none formally considered the impacts upon carers. The time spent providing informal care (such as personal care and household tasks) is a resource that is used up as a result of caring, and so carers should arguably be considered as a cost in economic evaluation. The carer's quality of life, however, may also be affected by a person's condition, and so outcomes for carers may also be relevant in an economic evaluation. Within the CUA framework, a new instrument the Carer Experience Scale (CES) which has been specifically designed for carers to measure and value the impact upon caring associated the introduction of new interventions may be particularly helpful. However, it has been argued that incorporating both carer costs and outcomes in the cost effectiveness ratio (CER) may result in double counting as carers may have considered their quality of life when valuing their time [63]. Other commentators suggest that carer effects may be accounted for on the cost side of the equation if monetary methods of valuing benefits are used and on the effects side when non-monetary methods of valuing benefits are applied [64, 65]. Another possible option is to move beyond assessment of quality of life within CUA and incorporate the wider impacts of an intervention upon the caring role in monetary terms within the framework of cost benefit analysis [66].

Overall, most of the interventions included in this review were not found to be cost effective, which was largely attributed to the short time horizons applied in these studies. A longer time horizon is recommended for service delivery interventions that involve the integration of various sectors and building of networks in service delivery such as in the community aged care sector to permit the intervention to go beyond the teething problems and adjustment phases to then observe the benefits attributed to the intervention $[34,37,67,68]$.

Strengths of this review include the systematic approach to data collection using a comprehensive search strategy in multi-disciplinary health databases and the geographical variation in the studies included that allowed for a snapshot of the evaluation of aged care services internationally. However, it was also a challenge as the aged care system and definition of services varies from one country to another and affects the comparability of the different studies. The review was also limited to empirical research published in the English language (model-based studies and grey literature were excluded) and full-text that could be accessed through the university library system.

\section{Conclusion}

In contrast to the high prevalence of economic evaluations conducted in the health care sector this systematic review has identified that relatively few economic evaluations have been conducted to date in the community aged care sector. The findings highlight the importance of cost utility analysis methodology as it allows for a uniform outcome measure, that facilitates the comparison of different interventions. Within cost utility analysis, multi-attribute utility measures that represent those quality of life domains that are most important to older people should be used and attention must be paid to the inclusion of informal care costs and outcomes as this is a key resource in community aged care service delivery. Future research should be directed towards developing methods and applications to facilitate the inclusion of carers effects in the economic evaluation of interventions for the community aged care sector.

\section{Abbreviations}

ASCOT: Adult social care outcomes toolkit; CCA: Cost consequence analysis; CEA: Cost effectiveness analysis; CINAHL: Cumulative index to nursing and allied health literature; CUA: Cost utility analysis; EQ-5D-3: EuroQol 5 Dimensions 3 level; GP: General practitioner; HRQoL: Health related quality of life; ICECAP-O: ICEpop capability measure for older people; LYS: Life years saved; PRISMA: Preferred reporting items for systematic reviews and metaanalyses; QALY: Quality adjusted life years; RCT: Randomised controlled trial; U: United Kingdom

\section{Acknowledgements}

Special thanks to Ms. Nikki May who helped with the database searches and acquisition of the data.

\section{Funding}

This work was supported through the award of an Australian Research Council Linkage Project, grant number LP110200079. Additional financial contributions were received from the following aged care organisations in Australia: ACH Group; Catholic Community Services; Hammondcare; Helping Hand and Resthaven. The funding bodies did not take part in the design of the study, collection, analysis, and interpretation of data and in writing the manuscript. 


\section{Availability of data and material}

Not applicable.

\section{Authors' contributions}

JR was responsible for study conception. NBB developed the systematic review protocol, conducted the review and wrote the first draft of the manuscript. BK and JR contributed to the development of the review protocol and revised the manuscript. All authors have seen and approved the final manuscript.

\section{Ethics approval and consent to participate}

Not applicable.

\section{Consent for publication}

Not applicable.

\section{Competing interests}

The authors declare that they have no competing interests.

\section{Publisher's Note}

Springer Nature remains neutral with regard to jurisdictional claims in published maps and institutional affiliations.

\section{Author details}

${ }^{1}$ Health Economics Unit, Flinders Health Care and Workforce Innovations, School of Medicine, Flinders University, Adelaide, SA, Australia. ${ }^{2}$ Institute for Choice, University of South Australia Business School, Adelaide, SA, Australia

\section{Received: 6 March 2018 Accepted: 2 December 2018}

Published online: 14 December 2018

\section{References}

1. World Health Organisation: Definition of an older or elderly person. In. 2002.

2. Department of Economic and Social Affairs: Population ageing and development: Ten years after Madrid. In: Population Facts. Population Division, United Nations 2012.

3. Department of Economic and Social Affairs Population Division. Population ageing and development: ten years after Madrid. In: Population Facts. United Nations; 2012.

4. Gray AM, Clarke PM, Wolstenholme JL, Wordsworth S. Applied methods of cost-effectiveness analysis in health care. United States: Oxford University Press; 2011

5. Drummond M, Sculpher MJ, Torrance GW, O'Brien BJ, Stoddart GL. Methods for the economic evaluation of health care programmes. 3rd ed. New York: Oxford University Press; 2005.

6. Guberman N, Lavoie J-P, Blein L, Olazabal I. Baby boom caregivers: Care in the age of individualization. The Gerontologist. 2012;52(2):210-8.

7. Richman A. Are Wii ready for the baby boomers? Long-Term Living. 2012; 61(4):24-6.

8. Robison J, Shugrue N, Fortinsky RH, Gruman C. Long-term supports and services planning for the future: implications from a statewide survey of baby boomers and older adults. Gerontologist. 2013.

9. Social care [https://www.gov.uk/government/topics/social-care]. Accessed 20 Sept 2018

10. What is Long-term care [https://www.nia.nih.gov/health/what-long-termcare]. Accessed 20 Sept 2018.

11. Damiani G, Farelli V, Anselmi A, Sicuro L, Solipaca A, Burgio A, lezzi DF, Ricciardi W. Patterns of long term care in 29 European countries: evidence from an exploratory study. BMC Health Serv Res. 2011;11(1):316.

12. Ottmann G, Allen J, Feldman P. A systematic narrative review of consumerdirected care for older people: implications for model development. Health Soc Care Community. 2013;21(6):563-81.

13. Productivity Commission: Trends in aged care services: some implications. In. Edited by Australian Government Productivity Commission, September 2008 edn. Canberra: Australian Government Productivity Commission; 2008.

14. Da Roit B, Le Bihan B. Similar and yet so different: cash-for-Care in six European Countries' long-term care policies. Milbank Q. 2010;88(3):286-309.

15. Gadsby EK. Personal Budgets and Health: A Review of the Evidence. In: Centre for Health Services Studies. Kent: University of Kent; 2013.
16. Health Foundation. Personal Health Budgets: Research scan. London: The Health Foundation; 2010

17. Ratcliffe J, Laver K, Couzner L, Crotty M: Health Economics and Geriatrics: Challenges and Opportunities. In: Geriatrics Edited by Prof Craig Atwood: InTech; 2012

18. Drummond MF, Sculpher MJ, Torrance GW, O'brien BJ, Stoddart GL Methods for the Economic Evaluation of Health Care Programs. New York: Oxford University Press; 2005.

19. Ratcliffe J, Laver K, Couzner L, Cameron ID, Gray L, Crotty M. Not just about costs: the role of health economics in facilitating decision making in aged care. Age Ageing. 2010;39(4):426-9.

20. Morris S, Devlin N, Parkin D: Economic Evaluation Methods. In: Economic Analysis in Health Care. Wiley.com; 2007a: 305

21. MSAC: Technical guidelines for preparing assessment reports for the medical services advisory committee in., vol. Medical Service Type: Therapeutic (Version 2.0) 2016.

22. NICE: Guide to the methods of technology appraisal 2013. In.; 2013.

23. Moher D, Liberati A, Tetzlaff J, Altman DG. The PG: preferred reporting items for systematic reviews and meta-analyses: the PRISMA statement. PLoS Med. 2009;6(7):e1000097.

24. Cohen J. A coefficient of agreement for nominal scales. Educ Psychol Meas. 1960;20:37-46.

25. Checklist for Economic Evaluation [http://www.gla.ac.uk/researchinstitutes/ healthwellbeing/research/generalpractice/ebp/checklists/]. Accessed 30 May 2015

26. Viera AJ, Garrett JM. Understanding Interobserver agreement: the kappa statistic. Fam Med. 2005;37(5):360-3.

27. Bouman A, Van Rossum E, Evers S, Ambergen T, Kempen G, Knipschild P. Effects on health care use and associated cost of a home visiting program for older people with poor health status: a randomized clinical trial in the Netherlands. J Gerontol A Biol Sci Med Sci. 2008;63(3):291-7.

28. Brettschneider C, Luck T, Fleischer S, Roling G, Beutner K, Sesselmann $Y$, Luppa M, Behrens J, Riedel-Heller S, Konig HH. Cost-utility analysis of a preventive home visit program for older adults in Germany. Value Health. 2014;17(7):A511.

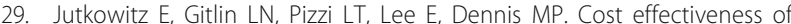
a home-based intervention that helps functionally vulnerable older adults age in place at home. J Aging Res. 2012;2012.

30. Melis RJF, Adang E, Teerenstra S, Van Eijken MIJ, Wimo A, Van Achterberg T, Van De Lisdonk EH, Olde Rikkert MGM: Cost-effectiveness of a multidisciplinary intervention model for community-dwelling frail older people. J Gerontol A Biol Sci Med Sciences 2008, 63(3):275-282.

31. Lewin GF, Alfonso HS, Alan JJ. Evidence for the long term cost effectiveness of home care reablement programs. Clin Interv Aging. 2013:8:1273-81

32. van Leeuwen $K M$, Bosmans JE, Jansen AP, Hoogendijk EO, Muntinga ME, van Hout HP, Nijpels G, van der Horst HE, van Tulder MW. Cost-effectiveness of a chronic care model for frail older adults in primary care: economic evaluation alongside a stepped-wedge cluster-randomized trial. J Am Geriatr Soc. 2015b;63(12):2494-504.

33. Fairhall N, Sherrington C, Kurrle SE, Lord SR, Lockwood K, Howard K, Hayes A, Monaghan N, Langron C, Aggar C, et al. Economic evaluation of a multifactorial, interdisciplinary intervention versus usual care to reduce frailty in frail older people. J Am Med Dir Assoc. 2015;16(1):41-8.

34. Looman WM, Huijsman R, Bouwmans-Frijters CAM, Stolk EA, Fabbricotti IN Cost-effectiveness of the 'Walcheren integrated care Model' intervention for community-dwelling frail elderly. Fam Pract. 2016:33(2):154-60.

35. Makai P, Looman W, Adang E, Melis R, Stolk E, Fabbricotti I. Costeffectiveness of integrated care in frail elderly using the ICECAP-O and EQ5D: does choice of instrument matter? The European journal of health economics : HEPAC : health economics in prevention and care. 2014a.

36. Flood C, Mugford M, Stewart S, Harvey I, Poland F, Lloyd-Smith W. Occupational therapy compared with social work assessment for older people. An economic evaluation alongside the CAMELOT randomised controlled trial. Age Ageing. 2005;34(1):47-52.

37. Sandberg M, Jakobsson U, Midlov P, Kristensson J. Cost-utility analysis of case management for frail older people: effects of a randomised controlled trial. Heal Econ Rev. 2015:5(1):51.

38. Brettschneider C, Luck T, Fleischer S, Roling G, Beutner K, Luppa M, Behrens $J$, Riedel-Heller SG, Konig H-H. Cost-utility analysis of a preventive home visit program for older adults in Germany. BMC Health Serv Res. 2015;15:141. 
39. EuroQol Group: EQ-5D. In.; 2014.

40. Ware JE Jr, Sherbourne CD. The MOS 36-item short-form health survey (SF36): I. Conceptual framework and item selection. Medical care. 1992:473-83.

41. Ware J, Kosinski M, Turner-Bowker D, Gandek B. How to score version 2 of the SF-12 health survey (with a supplement documenting version 1). Lincoln, Rl: Quality Metric; 2002.

42. Stewart AL, Hays RD, Ware JE Jr. The MOS short-form general health survey. Reliability and validity in a patient population. Med Care. 1988: 26(7):724-35.

43. Makai P, Brouwer WBF, Koopmanschap MA, Stolk EA, Nieboer AP. Quality of life instruments for economic evaluations in health and social care for older people: a systematic review. Soc Sci Med. 2014b;102:83-93.

44. Mauskopf JA, Paul JE, Grant DM, Stergachis A. The role of cost-consequence analysis in healthcare decision-making. Pharmacoeconomics. 1998;13(3):277-88.

45. Harris A, Bulfone L. Getting value for money: The Australian experience. In: Jost TS, editor. Health Care Coverage Determinations: An International Comparative Study. Maidenhead: Open University Press, McGraw-Hill International; 2004.

46. Ontario Ministry of Health and Long-term care: Ontario guidelines for economic analysis of pharmaceutical products. In: Ontario Ministry of Health and long-term care; 2006

47. Corbacho B, Pinto-Prades JL. Health economic decision-making: a comparison between UK and Spain. Br Med Bull. 2012;103(1):5-20.

48. National Institute for Health and Care Excellence. Guide to the methods of technology appraisal 2013. In: NICE; 2013.

49. Graybill EM, McMeekin P, Wildman J. Can aging in place be cost effective? A systematic review. PLoS ONE. 2014;9(7):e102705

50. Bowling A. Measuring health related quality of life among older people. Aging Ment Health. 1998;2(1):5-6.

51. Grewal I, Lewis J, Flynn T, Brown J, Bond J, Coast J. Developing attributes for a generic quality of life measure for older people: preferences or capabilities? Soc Sci Med. 2006;62(8):1891-901.

52. Ratcliffe J, Lancsar E, Flint T, Kaambwa B, Walker R, Lewin G, Luszcz M, Cameron ID. Does one size fit all? Assessing the preferences of older and younger people for attributes of quality of life. Qual Life Res. 2017;26(2):299-309.

53. Milte CM, Walker R, Luszcz MA, Lancsar E, Kaambwa B, Ratcliffe J. How important is health status in defining quality of life for older people? An exploratory study of the views of older south Australians. Applied health economics and health policy. 2014;12(1):73-84.

54. Bulamu NB, Kaambwa B, Ratcliffe J. A systematic review of instruments for measuring outcomes in economic evaluation within aged care. Health Qual Life Outcomes. 2015;13(1):1-23.

55. Milte R, Crotty M, Miller MD, Whitehead C, Ratcliffe J. Quality of life in older adults following a hip fracture: an empirical comparison of the ICECAP-O and the EQ-5D-3 L instruments. Health Qual Life Outcomes. 2018;16(1):173.

56. van Leeuwen KM, Bosmans JE, Jansen AP, Hoogendijk EO, van Tulder MW, van der Horst HE, Ostelo RW. Comparing measurement properties of the EQ-5D-3L, ICECAP-O, and ASCOT in frail older adults. Value Health. 2015; 18(1):35-43.

57. van Leeuwen KM, Jansen APD, Muntinga ME, Bosmans JE, Westerman MJ, van Tulder MW, van der Horst HE. Exploration of the content validity and feasibility of the EQ-5D-3L, ICECAP-O and ASCOT in older adults. BMC Health Serv Res. 2015;15(1):201.

58. Donaldson C, Atkinson A, Bond J, Wright K. Should QALYs be programmespecific? J Health Econ. 1988;7(3):239-57.

59. Donaldson C, Atkinson A, Bond J, Wright K. QALYS and long-term care for elderly people in the UK: scales for assessment of quality of life. Age Ageing. 1988;17(6):379-87.

60. Brazier J, Ratcliffe J, Salomon J, Tsuchiya A. Measuring and valuing health benefits for economic evaluation. Oxford: Oxford University Press; 2007.

61. Sanders GD, Neumann PJ, Basu A, Brock DW, Feeny D, Krahn M, Kuntz KM, Meltzer DO, Owens DK, Prosser LA, et al. Recommendations for conduct, methodological practices, and reporting of cost-effectiveness analyses: second panel on cost-effectiveness in health and medicine. Jama. 2016; 316(10):1093-103.

62. Goodrich K, Kaambwa B, Al-Janabi H. The inclusion of informal Care in Applied Economic Evaluation: a review. Value Health. 2012;15(6):975-81.

63. Koopmanschap MA, van Exel JNA, van den Berg B, Brouwer WBF. An overview of methods and applications to value informal Care in Economic Evaluations of healthcare. PharmacoEconomics. 2008;26(4): 269-80.
64. Hoefman RJ, van Exel J, Brouwer W. How to include informal Care in Economic Evaluations. PharmacoEconomics. 2013;31(12):1105-19.

65. Weatherly H, Faria R, Van den Berg B. Valuing Informal Care for Economic Evaluation. In: Culyer AJ, editor. Encyclopedia of health economics. San Diego: Elsevier; 2014. p. 459-67.

66. Drummond MF, Sculpher MJ, Torrance GW, O'brien BJ, Stoddart GL. Basic Types of Economic evaluation. In: Methods for the Economic Evaluation of Health Care Programs; 2005b. p. 7-26.

67. Simoens $\mathrm{S}$. Health economic assessment: a methodological primer. Int J Environ Res Public Health. 2009;6(12):2950-66.

68. McIntosh ES. Perspective on the economic evaluation of deep brain stimulation. Front Integr Neurosci. 2011;5:19.

\section{Ready to submit your research? Choose BMC and benefit from:}

- fast, convenient online submission

- thorough peer review by experienced researchers in your field

- rapid publication on acceptance

- support for research data, including large and complex data types

- gold Open Access which fosters wider collaboration and increased citations

- maximum visibility for your research: over $100 \mathrm{M}$ website views per year

At $\mathrm{BMC}$, research is always in progress.

Learn more biomedcentral.com/submissions 